\title{
Manipulação do Corte do Sorgo (Sorghum bicolor, L. Moench) para Confecção de Silagem, Visando a Produção do Novilho Superprecoce
}

\section{João Restle ${ }^{1}$, Mikael Neumann², Ivan Luiz Brondani ${ }^{3}$, Dari Celestino Alves Filho ${ }^{4}$, Regis Augusto Carvalho Bernardes ${ }^{5}$, Miguelangelo Ziegler Arboitte ${ }^{6}$, Joilmaro Rodrigo Pereira Rosa ${ }^{6}$}

\begin{abstract}
RESUMO - O experimento foi conduzido com o objetivo de estudar os parâmetros relativos ao consumo de alimentos, ganho de peso, conversão alimentar e eficiência energética de bezerros de corte em confinamento, alimentados com duas dietas, com inclusão de silagem de sorgo AG-2006 colhida em duas alturas de corte: corte baixo (14 cm) e corte alto (45 cm). Foram utilizados 12 bezerros Braford com idade média de sete meses e peso médio inicial de $208 \mathrm{~kg}$. O período de confinamento foi de 126 dias, subdividido em dois períodos de 63 dias, em que a relação volumoso:concentrado, para ambas as dietas testadas, foi de 60:40 e 50:50, respectivamente, para o primeiro e segundo períodos. A silagem produzida pelo corte alto apresentou menor teor de FDN (42,57 contra 52,24\%) e maior DIVMO (63,67 contra 53,59\%). Não houve interação entre altura de corte e período de avaliação em confinamento para os parâmetros relativos aos consumos diários de matéria seca (CMS) e de energia digestível (CED), expressos nas diferentes formas, ao ganho de peso médio diário (GMD) e à eficiência energética (CE). A elevação da altura de corte de 14 para $45 \mathrm{~cm}$ das plantas de sorgo para produção de silagem não afetou o CMS (7,60 contra 7,70 kg/dia), o CED (21,62 contra 23,83 Mcal/dia), o GMD (1,233 contra 1,375 kg) e a eficiência energética (17,53 contra 17,31 Mcal/kg de PV), respectivamente. Animais que tiveram a silagem de sorgo colhida a $45 \mathrm{~cm}$ incluída na dieta alimentar foram mais eficientes na transformação da matéria seca consumida em ganho de peso em relação à dieta com silagem de sorgo colhida a $14 \mathrm{~cm}$ de altura (5,60 contra $6,17 \mathrm{~kg}$ de $\mathrm{MS} / \mathrm{kg}$ de PV).
\end{abstract}

Palavras-chave: confinamento, consumo alimentar, conversão alimentar, ganho de peso, silagem de sorgo

\section{Sorghum (Sorghum bicolor, L. Moench) Cutting Height During Silage Processing for Young Beef Cattle Production}

\begin{abstract}
The experiment was conducted with the objective to evaluate the parameters of dry matter intake, weight gain, feed conversion and energy efficiency of young feedlot steers, fed with two diets that included the AG-2006 sorghum silage harvested with different cutting heights: low cut $(14 \mathrm{~cm})$ and high cut $(45 \mathrm{~cm})$. Twelve Braford calves with an average age of seven months and average live weight of $208 \mathrm{~kg}$, were used. The feedlot period was 126 days, divided in two period of the 63 days. The roughage:concentrate ratio was 60:40 during the first period and 50:50 during the second period. Silage produced with the higher cut showed lower NDF content (42.57 vs 52.24\%) and higher IVOMD (63.67 vs 53.59\%). No significant interaction was observed between roughage source and feedlot evaluation period for the consumption of dry matter (DMI) and digestible energy (CDE), expressed in their different forms, for average daily gain (ADG) and feed efficiency (FE). Raising the cutting height from 14 to $45 \mathrm{~cm}$ during silage processing, did not affect the DMI ( $7.60 \mathrm{vs} 7.70 \mathrm{~kg} / \mathrm{day})$, the CDE (21.62 vs $23.83 \mathrm{Mcal} /$ day), the ADG (1.233 vs $1.375 \mathrm{~kg}$ ) and the FE (17.53 vs $17.31 \mathrm{Mcal} / \mathrm{kg}$ of LW). Steers fed with silage obtained from the $45 \mathrm{~cm}$ cutting height were more efficient in converting dry matter intake into weight gain (5.60 vs $6.17 \mathrm{~kg}$ of $\mathrm{DM} / \mathrm{kg} \mathrm{LW}$ ).
\end{abstract}

Key Words: confinament, daily weight gain, dry matter intake, feed conversion, sorghum silage

\section{Introdução}

O confinamento de bovinos jovens é uma prática que vem sendo utilizada com maior freqüência nos últimos anos, por possibilitar a redução da idade de abate dos animais, resultando em melhor eficiência alimentar e na produção de carne de maior qualidade (Restle et al., 1999a). No entanto, a escolha e o balanceamento dos ingredientes que compõem a dieta alimentar são de fundamental importância, pois, segundo Restle et al. (2000a), a produção de animais jovens em confinamento requer adequadas concen-

\footnotetext{
${ }^{1}$ Engo-Agro, Ph.D., Pesquisador do CNPq, Professor Titular do Departamento de Zootecnia da UFSM - Campus Camobi, 97119-900, Santa Maria - RS. E mail: jorestle@ccr.ufsm.br

${ }^{2}$ Eng으-Agro, MSc.

3 Zootecnista, MSc., Professor do Departamento de Zootecnia da UFSM. E.mail: brondani@ccr.ufsm.br

${ }^{4}$ Engo-Agro ${ }^{\circ}$, MSc., Professor do Departamento de Zootecnia da UFSM. E.mail: dcafilho@ccr.ufsm.br

5 Zootecnista, MSc., Professor do Departamento de Zootecnia da UFSM. E.mail: racber@ccr.ufsm.br

${ }^{6}$ Zootecnista, Aluno do curso de Pós-Graduação da UFSM.
} 
trações de proteína bruta e energia digestível na dieta, visando atender a demanda de seu crescimento e terminação.

A ensilagem constitui-se, atualmente, no método de conservação de forragem mais utilizado no mundo. Segundo Neumann (2001), a cultura do sorgo para produção de silagem no país tem-se mostrado como uma alternativa viável aos produtores, principalmente em regiões que apresentam particularidades edafoclimáticas que limitam o cultivo ou o potencial produtivo da cultura do milho. Segundo Zago (1991), o sorgo é uma planta forrageira que apresenta facilidade de cultivo, altos rendimentos de matéria seca por unidade de área e qualidade da silagem produzida. No entanto, Demarchi et al. (1995) ressaltam que o valor nutritivo da silagem de sorgo equivale de 72 a $92 \%$ da silagem de milho. Tais aspectos condicionam a possibilidade de manipulação do processo de colheita do sorgo para ensilagem, visto que a elevação da altura de corte das plantas permite maior participação de grãos na massa ensilada, resultando, segundo Restle et al. (1999c), em decréscimos significativos nos teores de fibra em detergente neutro e detergente ácido da silagem. De acordo com Silva et al. (1999b), as porcentagens de colmo e de panícula, sejam para o milho ou para o sorgo, são as características agronômicas mais alta e consistentemente correlacionadas com medidas de qualidade da silagem, como digestibilidade da MS e FDA, ganho de peso médio diário e consumo de matéria seca. Pund (1970) considera que o aumento da proporção de grãos na silagem promove maior concentração de energia, devido à redução do teor de lignina e ao aumento da digestibilidade. Já Hart (1990) verificou que a elevação da altura de corte das plantas de sorgo propiciou maior concentração de amido e menores teores de FDN e FDA na silagem, não observando influência sobre a digestibilidade.

O objetivo do presente trabalho foi avaliar o efeito da manipulação da altura de corte das plantas de sorgo para produção de silagem sobre os parâmetros relativos ao consumo de alimentos, ao ganho de peso médio diário, à conversão alimentar e eficiência energética de bezerros de corte terminados em confinamento.

\section{Material e Métodos}

O experimento foi conduzido no Setor de Bovinocultura de Corte do Departamento de Zootecnia da Universidade Federal de Santa Maria, localizada fisiograficamente na Depressão Central do Estado do Rio Grande do Sul, a uma altitude de $95 \mathrm{~m}$. Cartograficamente, se localiza a $29^{\circ} 43^{\prime}$ de latitude Sul e $53^{\circ} 42^{\prime}$ de longitude Oeste (BRASIL, 1973).

O clima da região é o Cfa (subtropical úmido), conforme classificação de Köppen, com precipitação média anual de $1.769 \mathrm{~mm}$, temperatura média anual de $19,2^{\circ} \mathrm{C}$, com média mínima de $9,3^{\circ} \mathrm{C}$ em julho e média máxima de $24,7^{\circ} \mathrm{C}$ em janeiro, insolação de 2.212 horas anuais e umidade relativa do ar de $82 \%$ (Moreno, 1961).

Os tratamentos testados corresponderam às dietas alimentares, na terminação de bezerros de corte, que incluíram a silagem do híbrido de sorgo AG-2006 colhida a duas alturas de corte das plantas: T14 - corte baixo $(14 \mathrm{~cm})$ e T45 - corte alto $(45 \mathrm{~cm})$.

O híbrido de sorgo AG-2006 com características de duplo propósito foi utilizado na ocasião, devido à sua estabilidade de adaptação as condições climáticas e ao seu pronunciado potencial produtivo e qualitativo para produção de silagem no sul do Brasil frente aos demais materiais genéticos oferecidos pelas empresas de melhoramento. As silagens foram produzidas em uma área com características de manejo e fertilidade de solo adequadas ao cultivo do sorgo, sendo colhidas quando a massa das plantas apresentavam entre $33 \mathrm{e}$ $35 \%$ de matéria seca, com auxílio de uma ensiladeira regulada com tamanho médio de picado de 1 a $1,5 \mathrm{~cm}$. O material colhido foi armazenado e compactado com auxílio de um trator, em silos de superfície tipo "torta", vedados e protegidos com lona plástica de polietileno de três camadas.

A alimentação e a avaliação do desempenho e consumo de alimentos dos animais compreendeu o período de 12 de junho a 15 de outubro de 1997 , totalizando 126 dias de confinamento, sendo subdividido em dois períodos de avaliação de 63 dias.

A relação volumoso:concentrado para ambas dietas experimentais (T14 - corte baixo e T45 - corte alto), com base na matéria seca, foi de 60:40 e 50:50, respectivamente, para o primeiro e segundo períodos de avaliação do confinamento. As dietas alimentares oferecidas aos bezerros foram isoprotéicas com $12,8 \%$ de proteína bruta para o primeiro e segundo períodos de avaliação. A composição das dietas experimentais encontra-se na Tabela 1.

A alimentação foi ad libitum, sendo os alimentos fornecidos duas vezes ao dia, pela manhã às $8 \mathrm{~h}$ e a tarde às $16 \mathrm{~h}$. $\mathrm{O}$ ajuste do fornecimento da quantidade de alimento in natura foi calculado diariamente, consi- 
Tabela 1 - Composição percentual dos ingredientes nas dietas experimentais, com base na matéria seca total Table 1 - Composition (\%) of the experimental diets, total dry matter basis

\begin{tabular}{|c|c|c|c|c|}
\hline \multirow[t]{3}{*}{$\begin{array}{l}\text { Constituintes } \\
\text { Components }\end{array}$} & \multicolumn{4}{|c|}{$\begin{array}{l}\text { Períodos de avaliação } \\
\text { Evaluation periods }\end{array}$} \\
\hline & \multicolumn{2}{|c|}{$\begin{array}{c}12 / 06 \text { a } 13 / 08 / 1997 \\
06 / 12 \text { to } 08 / 13\end{array}$} & \multicolumn{2}{|c|}{$\begin{array}{c}14 / 08 \text { a } 16 / 10 / 1997 \\
08 / 14 \text { to } 10 / 16\end{array}$} \\
\hline & $\begin{array}{c}\text { Corte baixo } \\
(14 \mathrm{~cm}) \\
\text { Low cut } \\
(14 \mathrm{~cm})\end{array}$ & $\begin{array}{c}\text { Corte alto } \\
(45 \mathrm{~cm}) \\
H i g h \mathrm{cut} \\
(45 \mathrm{~cm})\end{array}$ & $\begin{array}{c}\text { Corte baixo } \\
(14 \mathrm{~cm}) \\
\text { Low cut } \\
(14 \mathrm{~cm})\end{array}$ & $\begin{array}{c}\text { Corte alto } \\
(45 \mathrm{~cm}) \\
H i g h \mathrm{cut} \\
(45 \mathrm{~cm})\end{array}$ \\
\hline $\begin{array}{l}\text { Volumoso (Silagem de sorgo) } \\
\text { Roughage (Sorghum silage) } \\
\text { Concentrado }\end{array}$ & 60,00 & 60,00 & 50,00 & 50,00 \\
\hline $\begin{array}{l}\text { Concentrate } \\
\text { - Farelo de soja } \\
\text { - Soybean meal }\end{array}$ & 12,16 & 12,16 & 11,26 & 11,26 \\
\hline $\begin{array}{l}\text { - Sorgo grão } \\
\text { - Sorghum grain }\end{array}$ & 22,74 & 22,74 & 32,24 & 32,24 \\
\hline $\begin{array}{l}\text { - Farelo de arroz desengordurado } \\
\text { - Rice bran }\end{array}$ & 4,00 & 4,00 & 5,00 & 5,00 \\
\hline $\begin{array}{l}\text { - Sal comum } \\
\text { - Salt }\end{array}$ & 0,70 & 0,70 & 1,25 & 1,25 \\
\hline $\begin{array}{l}\text { - Calcário calcítico } \\
\text { - Limestone }\end{array}$ & 0,40 & 0,40 & 0,25 & 0,25 \\
\hline $\begin{array}{l}\text { Total } \\
\text { Total }\end{array}$ & 100,00 & 100,00 & 100,00 & 100,00 \\
\hline
\end{tabular}

derando uma sobra de $10 \%$ da matéria seca oferecida em relação à consumida. Primeiramente, foi distribuído o volumoso no comedouro e sobre o mesmo o concentrado, realizando-se em seguida a mistura. $\mathrm{O}$ consumo voluntário dos alimentos foi registrado diariamente por meio da pesagem da quantidade oferecida e das sobras do dia anterior.

Foram utilizados 12 bezerros, da raça Braford (5/8 Hereford 3/8 Nelore), com idade média de sete meses e peso vivo médio inicial de $208 \mathrm{~kg}$, distribuídos em quatro baias de confinamento com três animais cada. Os animais foram submetidos a um período de 18 dias de adaptação às instalações e às dietas experimentais. Neste período, realizou-se a aplicação de um vermífugo de amplo espectro.

Os animais foram pesados, após um jejum de sólidos de 12 horas, no início e no final do período experimental, com pesagens intermediárias a cada 21 dias.

Foram coletadas amostras representativas dos componentes da dieta alimentar no início da adaptação e a cada período de avaliação do experimento. Estas amostras foram pré-secas em estufa de ar forçado a $60^{\circ} \mathrm{C}$ por 72 horas, para determinação do teor de matéria seca, sendo seqüencialmente processadas em moinho tipo "Willey", com peneira de malha de um milímetro. Posteriormente, nas amostras de cada alimento, foram determinados o teor de matéria seca total (MS) e o teor de matéria mineral (MM) por incineração a $550^{\circ} \mathrm{C}$, obtendo-se por diferença o teor de matéria orgânica $(\mathrm{MO}=100$ $\mathrm{MM}$ ) e nitrogênio total pelo método micro kjeldahl, o qual foi multiplicado pelo fator 6,25 para obtenção do teor de proteína bruta (PB), conforme AOAC (1984), e a digestibilidade in vitro da matéria orgânica (DIVMO) (Tilley \& Terry, 1963). Os teores de fibra em detergente neutro (FDN) e fibra em detergente ácido (FDA) foram determinados pelo método descrito por Van Soest \& Wine (1967). Para o cálculo de energia digestível (ED), utilizaram-se as equações descritas pelo ARC (1980), com base na digestibilidade in vitro da matéria orgânica (DIVMO) e matéria orgânica (MO), sendo calculado, a partir desta, a energia metabolizável (EM), multiplicando-se a ED pelo fator 0,82 .

Os parâmetros estimados foram consumo médio diário de matéria seca (CMS), expresso em kg/animal (CMSD), por $100 \mathrm{~kg}$ de peso vivo (CMSP) e por unidade de tamanho metabólico (CMSM), bem como 
o consumo médio diário de energia digestível (CED), expresso em Mcal/animal (CEDD), por $100 \mathrm{~kg}$ de peso vivo (CEDP) e por unidade tamanho metabólico (CEDM), ganho de peso médio diário (GMD), conversão alimentar (CA) e eficiência energética (CE).

O comportamento produtivo da lavoura e a composição física percentual da estrutura da planta de sorgo das silagens avaliadas foram comparados por intermédio de análise descritiva amostral dos dados coletados.

O delineamento experimental foi o inteiramente casualizado, composto por dois tratamentos (dietas com silagem de sorgo colhida às alturas de corte de 14 ou $45 \mathrm{~cm}$ ), com duas repetições. Cada unidade experimental foi composta por um lote de três animais.

Os dados coletados de cada parâmetro foram submetidos à análise de variância por intermédio do pacote estatístico SAS (1993) e as diferenças entre as médias, analisadas pelo teste de F, a 5\% de significância.

$\mathrm{O}$ modelo estatístico utilizado foi o seguinte:

$\mathrm{Y}_{\mathrm{ijk}}=\mu+\mathrm{AC}_{\mathrm{i}}+\mathrm{R}_{\mathrm{j}}(\mathrm{AC})_{\mathrm{i}}+\mathrm{P}_{\mathrm{k}}+(\mathrm{AC} * \mathrm{P})_{\mathrm{ik}}+\mathrm{E}_{\mathrm{ijk}}$ em que: $Y_{i j k}=$ variáveis dependentes; $\mu=$ Média das observações; $\mathrm{AC}_{\mathrm{i}}=$ efeito da altura de corte de ordem "i", sendo 1 (silagem de sorgo colhida à altura de corte de $14 \mathrm{~cm}$ ) e 2 (silagem de sorgo colhida à altura de corte de $45 \mathrm{~cm}) ; \mathrm{R}_{\mathrm{j}}(\mathrm{AC})_{\mathrm{i}}=$ efeito aleatório baseado na repetição dentro do tratamento (ACi) (Erro a); $\mathrm{P}_{\mathrm{k}}=$ efeito do período de avaliação de ordem "k", sendo 1 o primeiro período, com relação volumoso:concentrado de 60:40 e 2 o segundo período, com relação volumoso:concentrado de 50:50; $\left(A C^{*} \mathrm{P}\right)_{\mathrm{ik}}=$ efeito da interação entre o tratamento altura de corte de ordem "i" e período de avaliação de ordem "k"; $\mathrm{E}_{\mathrm{ijkl}}=$ erro aleatório residual, assumindo distribuição normal média igual a zero e variância $\sigma^{2}$ (Erro b).

\section{Resultados e Discussão}

Verifica-se na Tabela 2 que a silagem de sorgo do híbrido AG-2006 apresentou menor teor de matéria seca (MS) e maior concentração de energia digestível (ED) por $\mathrm{kg}$ de matéria seca quando colhida a $45 \mathrm{~cm}$ de altura $(34,38 \%$ e $2,784 \mathrm{Mcal})$ em relação à silagem colhida a $14 \mathrm{~cm}$ de altura $(38,47 \%$ e $2,323 \mathrm{Mcal})$. Para o teor de PB os valores foram similares entre as silagens produzidas com alturas de corte de $14 \mathrm{~cm}$ $(6,63 \%)$ e $45 \mathrm{~cm}(6,56 \%)$.

Conforme pode ser observado na Tabela 2, a elevação da altura de colheita das plantas de sorgo de

Tabela 2 - Teores médios percentuais de matéria seca (MS), digestibilidade in vitro da matéria orgânica (DIVMO), matéria orgânica (MO), proteína bruta (PB), fibra em detergente neutro (FDN), fibra em detergente ácido (FDA), energia digestível (ED) e energia metabolizável (EM) dos componentes das dietas experimentais, com base na matéria seca total

Table 2 - Average percentages of dry matter (DM), in vitro organic matter digestibility (IVOMD), organic matter (OM), crude protein $(C P)$, neutral detergent fiber (NDF), acid detergent fiber (ADF), digestible energy (DE) and metabolizable energy (ME) of the diets components, total dry matter basis

\begin{tabular}{|c|c|c|c|c|c|}
\hline \multirow[t]{2}{*}{$\begin{array}{l}\text { Variável } \\
\text { Variable }\end{array}$} & \multirow[t]{2}{*}{$\begin{array}{r}\text { Farelo de soja } \\
\text { Soybean meal }\end{array}$} & \multirow[t]{2}{*}{$\begin{array}{l}\text { Sorgo grão } \\
\text { Sorghum grain }\end{array}$} & \multirow[t]{2}{*}{$\begin{array}{l}\text { Farelo de arroz des. } \\
\text { Rice bran }\end{array}$} & \multicolumn{2}{|c|}{$\begin{array}{l}\text { Altura de corte } \\
\text { Cutting height }\end{array}$} \\
\hline & & & & $\begin{array}{c}\text { Corte baixo }(14 \mathrm{~cm}) \\
\text { Low cut }(14 \mathrm{~cm})\end{array}$ & $\begin{array}{c}\text { Corte alto }(45 \mathrm{~cm}) \\
\text { High cut }(45 \mathrm{~cm})\end{array}$ \\
\hline $\begin{array}{l}\mathrm{MS}(D M) \\
\mathrm{DIVMO}(I V O M D)\end{array}$ & $\begin{array}{l}90,01 \\
82,67\end{array}$ & $\begin{array}{l}89,98 \\
82,26\end{array}$ & $\begin{array}{l}\cdots \cdots \\
88,21 \\
65,40\end{array}$ & 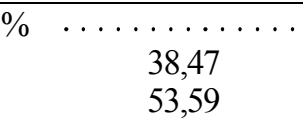 & $\begin{array}{l}34,38 \\
63,67\end{array}$ \\
\hline & & & $\cdots \cdots \frac{0}{0}$ & $\begin{array}{l}\text { MS } \\
D M\end{array}$ & \\
\hline $\mathrm{MO}(O M)$ & 94,73 & 99,19 & 92,14 & 95,37 & 96,20 \\
\hline $\mathrm{PB}(C P)$ & 50,58 & 9,19 & 15,88 & 6,63 & 6,56 \\
\hline $\mathrm{FDN}(N D F)$ & $14,90 *$ & $16,10^{*}$ & $18,0^{*}$ & 52,24 & 42,57 \\
\hline $\operatorname{FDA}(A D F)$ & $10,00 *$ & $6,38^{*}$ & $13,0^{*}$ & 28,44 & 25,48 \\
\hline & & & $\begin{array}{r}\ldots . M c a l \\
\text { Mcal }\end{array}$ & $\begin{array}{l}\text { g de } \mathrm{MS} \text {. } \\
\text { of } D M\end{array}$ & \\
\hline $\mathrm{ED}(D E)$ & 3,560 & 3,709 & 2,739 & 2,323 & 2,784 \\
\hline $\operatorname{EM}(M E)$ & 2,919 & 3,041 & 2,246 & 1,905 & 2,283 \\
\hline
\end{tabular}

* Dados compilados do NRC (1984).

* Data taken from NRC (1984).

R. Bras. Zootec., v.31, n.3, p.1481-1490, 2002 (suplemento) 
14 para $45 \mathrm{~cm}$ proporcionou redução de $18,51 \mathrm{e}$ $10,41 \%$ nos teores de FDN e FDA da silagem produzida, respectivamente, assim como aumento percentual na ordem de $18,81 \%$ no coeficiente de DIVMO. Silva (1999), avaliando a silagem de sorgo AG-2006 na terminação de novilhos confinados, observou valores de $33,53 \%$ de $\mathrm{MS}, 7,22 \%$ de $\mathrm{PB}$, $95,85 \%$ de MO, $52,53 \%$ de FDN e $28,89 \%$ de FDA. Já Eifert (2000), utilizando silagem de sorgo AG-2006 colhida à altura de $19 \mathrm{~cm}$, observou valores de $31,20 \%$ de MS, $7,38 \%$ de PB, $94,82 \%$ de $\mathrm{MO}, 59,63 \%$ de FDN e $27,26 \%$ de FDA.

Hart (1990), avaliando a concentração de grãos de sorgo na massa ensilada, verificou que a elevação da altura de colheita das plantas de sorgo propiciou maior concentração de amido e menores teores de FDN e FDA na silagem, porém não observou influência da altura de corte sobre a DIVMO. Zago (1991) e Neumann (2001) evidenciaram que a panícula é o componente estrutural da planta responsável pelo valor nutritivo da silagem, devido ao maior coeficiente de digestibilidade frente aos componentes colmo e folhas. Já Silva et al. (1999b), trabalhando com silagens de sorgo com diferentes proporções de colmo+folhas/ panícula, concluíram que o aumento de panículas na massa ensilada reduziu os teores dos constituintes da fibra e elevou os valores de DIVMS.

Fica evidente no presente trabalho que a diminuição nas concentrações de FDN e FDA e o aumento na DIVMO da silagem de sorgo do híbrido AG-2006 colhida a $45 \mathrm{~cm}$ foram resultados da elevação da altura de corte das plantas. Este sistema de manejo de colheita contribuiu para maior participação do componente panícula na massa ensilada (Tabela 3), o que possibilitou a associação de melhores características qualitativas ao elevado potencial de produção do híbrido AG-2006.
Constam na Tabela 3 as características agronômicas do híbrido AG-2006, de acordo com a manipulação da altura de colheita das plantas para ensilagem. O híbrido AG-2006 foi cultivado com espaçamento entre linhas de $0,90 \mathrm{~m}$ e no momento do processo de ensilagem apresentou uma população de 102.431 plantas/ha, o que determinou uma produção total de matéria verde de $43.821 \mathrm{~kg} / \mathrm{ha}$, porém, com o sistema de colheita das plantas às alturas de 14 e $45 \mathrm{~cm}$, provocou, respectivamente, a remanescência de 7,4 e $23,2 \%$ da porção basal das planta na lavoura.

O sistema de colheita à altura de $14 \mathrm{~cm}$ propiciou incremento na ordem de $17,20 \%$ na produção de matéria verde ensilável em relação à altura de corte de $45 \mathrm{~cm}$ (40.594 contra $33.613 \mathrm{~kg} / \mathrm{ha}$ ), enquanto a produção de matéria seca ensilável estimada apresentou incremento na ordem de 29,38\% (15.617 contra $11.556 \mathrm{~kg} / \mathrm{ha}$ ). Este fato é justificado pelos teores de MS da massa das plantas colhidas no momento da ensilagem, em que se verificou maior teor de MS no sistema de colheita com altura de corte a $14 \mathrm{~cm}(39,94 \%)$, comparativamente ao realizado com altura de $45 \mathrm{~cm}(34,06 \%)$, devido à maior participação das frações senescentes localizadas na região basal da planta (colmo e folhas secas) com elevados teores de MS.

$\mathrm{Na}$ composição física percentual das estruturas anatômicas da massa ensilada (Tabela 3), verifica-se que a elevação da altura de corte das plantas de sorgo para $45 \mathrm{~cm}$ promoveu maior participação do componente panícula $(41,0$ contra $33,1 \%)$ e folhas $(28,2$ contra $23,5 \%)$ e menor participação de colmo $(30,8$ contra $43,4 \%)$ na massa ensilada, comparativamente ao sistema de colheita tradicional com altura de corte de $14 \mathrm{~cm}$. A maior participação do componente panícula e folhas íntegras conferiu maior concentração de ED por kg de MS da silagem

Tabela 3 - Altura de planta $(H)$, produção de matéria verde (MV), produção de matéria seca (MS) e composição física percentual da planta, baseado na altura de corte

Table 3 - Plant height (H), green matter production (GM), dry matter production (DM) and percentage of plant physical components, based on cutting height

\begin{tabular}{|c|c|c|c|c|c|c|}
\hline \multirow[t]{2}{*}{$\begin{array}{l}\text { Tratamento } \\
\text { Treatment }\end{array}$} & \multirow[t]{2}{*}{$\begin{array}{l}\mathrm{H} \\
(\mathrm{cm})\end{array}$} & \multirow[t]{2}{*}{$\begin{array}{r}\mathrm{MV}(\mathrm{GM}) \\
\ldots \ldots\end{array}$} & \multirow[t]{2}{*}{$\begin{array}{l}\mathrm{MS}(\mathrm{DM}) \\
\ldots \ldots\end{array}$} & \multicolumn{3}{|c|}{$\begin{array}{l}\text { Composição (\%) } \\
\text { Composition (\%) }\end{array}$} \\
\hline & & & & $\begin{array}{c}\text { Colmo } \\
\text { Stem }\end{array}$ & $\begin{array}{l}\text { Folhas } \\
\text { Leaves }\end{array}$ & $\begin{array}{r}\text { Panícula } \\
\text { Panicle } \\
\end{array}$ \\
\hline $\begin{array}{l}\text { Corte baixo }(14 \mathrm{~cm}) \\
\text { Low cut }(14 \mathrm{~cm})\end{array}$ & 256 & 40.594 & 16.213 & 43,4 & 23,5 & 33,1 \\
\hline $\begin{array}{l}\text { Corte alto }(45 \mathrm{~cm}) \\
\text { High cut }(45 \mathrm{~cm})\end{array}$ & 256 & 33.613 & 11.449 & 30,8 & 28,2 & 41,0 \\
\hline
\end{tabular}


produzida com o corte das plantas a $45 \mathrm{~cm}$ (Tabela 2) em relação ao corte de $14 \mathrm{~cm}$ (2,784 contra 2,323 $\mathrm{Mcal} / \mathrm{kg}$ de MS). Silva et al. (1999a), avaliando o híbrido AG-2006, verificou altura de planta de $238 \mathrm{~cm}$, produção de MV de $35.289 \mathrm{~kg} / \mathrm{ha}$ e participação média de $37 \%$ de folhas, $18 \%$ de colmo e $45 \%$ de panícula na estrutura física da planta.

$\mathrm{Na}$ Tabela 4 são apresentados os resultados médios do CMS, expressos em $\mathrm{kg} / \mathrm{dia}$ de $\mathrm{MS}$, em relação a $100 \mathrm{~kg}$ de peso vivo e ao peso corporal metabólico, de acordo com a fonte de volumoso testada e com o período de avaliação. Não houve

Tabela 4 - Consumo médio diário de matéria seca (CMS), expresso por kg/animal (CMSD), por $100 \mathrm{~kg}$ de peso vivo (CMSP) e por unidade de peso metabólico (CMSM), de bezerros confinados, de acordo com o tratamento e período de avaliação

Table 4 - Average daily dry matter intake (DMI), expressed in $\mathrm{kg}$ per animal (DMID), per $100 \mathrm{~kg}$ of live weight (DMIP) , per unit of metabolic weight (DMIM), of confined calves, according to treatment and evaluation period

\begin{tabular}{|c|c|c|c|}
\hline \multirow{2}{*}{$\begin{array}{l}\text { Tratamento } \\
\text { Treatment }\end{array}$} & \multicolumn{2}{|c|}{$\begin{array}{l}\text { Períodos de avaliação } \\
\text { Evaluation periods }\end{array}$} & \multirow[t]{2}{*}{$\begin{array}{l}\text { Média } \\
\text { Mean }\end{array}$} \\
\hline & $\begin{array}{l}12 / 06 \text { a } 13 / 08 \\
06 / 12 \text { to } 08 / 13\end{array}$ & $\begin{array}{l}14 / 08 \text { a } 16 / 10 \\
08 / 14 \text { to } 10 / 16\end{array}$ & \\
\hline \multicolumn{4}{|c|}{ CMSD $(\mathrm{kg} /$ dia $)$. } \\
\hline $\begin{array}{l}\text { Corte baixo } \\
\text { Low cut }\end{array}$ & 6,76 & 8,45 & $7,60^{\mathrm{A}}$ \\
\hline $\begin{array}{l}\text { Corte alto } \\
\text { High cut }\end{array}$ & 6,81 & 8,59 & $7,70^{\mathrm{A}}$ \\
\hline $\begin{array}{l}\text { Média } \\
\text { Mean }\end{array}$ & $6,79^{b}$ & $8,52^{\mathrm{a}}$ & \\
\hline
\end{tabular}

Mean

$\begin{array}{lrccc} & \ldots \ldots \ldots & \mathrm{CMSP}(\% \mathrm{PV}) & \ldots \ldots \ldots & \\ \begin{array}{l}\text { Corte baixo } \\ \text { Low cut }\end{array} & 2,75 & & 2,61 & 2,68^{\mathrm{A}} \\ \begin{array}{l}\text { Corte alto } \\ \text { High cut }\end{array} & 2,70 & & 2,54 & 2,62^{\mathrm{A}} \\ \begin{array}{l}\text { Média } \\ \text { Mean }\end{array} & 2,73^{\mathrm{a}} & & 2,57^{\mathrm{b}} & \end{array}$

Mean

CMSM $\left(\mathrm{g} / \mathrm{kg}^{0,75}\right)$ $D M I M$

$\begin{array}{lccc}\begin{array}{l}\text { Corte baixo } \\ \text { Low cut }\end{array} & 108,9 & 110,8 & 109,8^{\mathrm{A}} \\ \begin{array}{l}\text { Corte alto } \\ \text { High cut }\end{array} & 107,7 & 108,8 & 108,3^{\mathrm{A}} \\ \begin{array}{l}\text { Média } \\ \text { Mean }\end{array} & 108,3^{\mathrm{a}} & 109,8^{\mathrm{a}} & \end{array}$

Mean

A,B,a,b Médias, na coluna, seguidas de letras maiúsculas diferentes e médias, na linha, seguidas de letras minúsculas diferentes para cada variável, diferem $(P<0,05)$.

$A, B, a, b \quad$ Means, within a column, followed by different capital letters and means, within a line, followed by different small letters, are different $(P<.05)$

R. Bras. Zootec., v.31, n.3, p.1481-1490, 2002 (suplemento) interação $(\mathrm{P}>0,05)$ entre fonte de volumoso e período de avaliação para CMS e CED, expressos nas diferentes formas.

Os CMS, quando expressos nas diferentes formas, não foram afetados $(\mathrm{P}>0,05)$ pela altura de corte das plantas ensiladas. Observa-se que o corte a $45 \mathrm{~cm}$ favoreceu o CMSD (7,70 kg/dia), enquanto o corte a $14 \mathrm{~cm}$ favoreceu o CMSP $(2,68 \%)$ e o CMSM (109,8 g/ $\left.\mathrm{kg}^{0,75}\right)$. Mertens (1992) relata que existe uma relação inversa entre a concentração de FDN da dieta e o consumo voluntário de alimentos, em que altos teores de FDN dos alimentos utilizados na dieta alimentar tendem a limitar a ingestão de MS devido a ocupação do espaço do trato gastrointestinal. Já McDonald et al. (1991) ponderam que o consumo voluntário dos animais se relaciona intimamente com o conteúdo de MS da silagem.

Pereira et al. (1993), trabalhando com silagens de híbridos de sorgo de comportamento agronômico diferenciado, observaram a tendência de aumento do CMSD das silagens com maior conteúdo de MS associado à maior proporção grãos:massa verde. Elizalde (1995) ressalta que a resposta do consumo voluntário dos animais depende, entre outros fatores, da qualidade de fermentação da massa ensilada, a qual é definida principalmente pelo conteúdo de MS do material original. Trabalhos de pesquisa realizados por Silva (1999) e Eifert (2000), ambos utilizando silagem de sorgo AG-2006, revelaram que o CMSD é influenciado pela concentração de FDN dos alimentos, fato também relatado por Restle et al. (2000b), utilizando palha de soja em substituição à silagem de sorgo na alimentação de bezerros de corte confinados, onde verificaram que o aumento no nível de palha de soja causou a diminuição linear do CMS, devido ao elevado teor de fibra e baixa digestibilidade da palha.

Embora a silagem com corte a $14 \mathrm{~cm}$ tenha apresentado maior concentração de FDN (52,24 contra 42,57\%), o que poderia resultar em menor CMS (Mertens, 1992; Silva, 1999; Eifert, 2000), esta apresentou maior teor de MS (38,47 contra $34,38 \%)$, o que favoreceria o CMS (McDonald et al., 1991; Pereira et al., 1993; Elizalde, 1995). A combinação destes dois fatores, conteúdos de MS e FDN, deve ter sido a causa da diferença não-significativa do CMS entre as duas silagens.

Vargas Jr. et al. (1998), avaliando o desempenho de bezerros de corte utilizando dietas com relação volumoso concentrado de 45:55, sendo o volumoso silagem de sorgo AG-2005E colhida às alturas de 20 
e $45 \mathrm{~cm}$, verificaram maior CMSD para os animais cuja dieta incluiu silagem de corte alto em relação à silagem de corte baixo (7,14 contra $6,51 \mathrm{~kg} / \mathrm{dia})$.

Silva (1999), utilizando silagem de sorgo AG-2006 em dietas com relação volumoso:concentrado de 65:35 e 55:45, observou CMSP de 2,65 e 2,61\%, respectivamente, sendo similares ao do presente experimento. Já Silva et al. (1999a), trabalhando com silagem de sorgo AG-2006 em dietas com relação volumoso:concentrado de 70:30, na terminação novilhos puros Nelore e mestiços F1 Pardo Suíço x Nelore, observaram CMSP de 2,30 e 2,13\%, respectivamente, enquanto Pimentel et al. (1998), utilizando silagem de sorgo de duplo propósito na dieta de bezerros, observaram CMSP e CMSM de 2,89\% e $99,07 \mathrm{~g} / \mathrm{kg}^{0,75}$, respectivamente.

O CMSD e o CMSP foram afetados $(\mathrm{P}<0,05)$ pelo período de avaliação (Tabela 4). Maiores CMSD $(\mathrm{P}<0,05)$ médios foram observados no segundo período de avaliação $(8,52 \mathrm{~kg} /$ dia $)$, comparativamente à média do primeiro período $(6,79 \mathrm{~kg} / \mathrm{dia})$. O aumento percentual de 25,48\% no CMSD é justificado pelo desenvolvimento corporal dos animais, com o avanço do período de confinamento, bem como pelo incremento na ordem de $10 \%$ na fração concentrada da composição da dieta dos animais (Tabela 1), responsável pela palatabilidade, densidade protéica e energética, além do aumento do teor de MS, e pelos decréscimos dos teores de FDN e FDA das dietas. Eifert (2000), trabalhando com dietas contendo silagem de sorgo AG-2006 associada a diferentes níveis de concentrado, observou que o CMSD dos animais em confinamento aumentou linearmente com a quantidade de matéria seca presente em cada dieta, sugerindo que a quantidade de volumoso presente na dieta, associado a maiores conteúdos de água, determina o espaço ocupado no rúmen, podendo vir a limitar o consumo pelo efeito de distensão ruminal.

O CMSP (Tabela 4) apresentou comportamento contrário ao CMSD, verificando-se maiores consumos para o primeiro período (2,73 contra $2,57 \% \mathrm{PV})$ comparativamente ao segundo período, enquanto para o CMSM (108,3 contra $\left.109,8 \mathrm{~g} / \mathrm{kg}^{0,75}\right)$ não foi observada diferença significativa entre os períodos de avaliação. Mertens (1994) e Valadares Filho et al. (1997) consideram que a variação do consumo de alimentos durante a fase de desenvolvimento corporal de bovinos de corte é melhor expressa como a taxa do consumo em relação ao peso vivo do animal e que o comportamento de ingestão de alimentos tende a decrescer com o avanço do desenvolvimento corporal.
$\mathrm{Na}$ Tabela 5 constam os dados relativos ao consumo de energia digestível, que é o resultado da associação da concentração energética das silagens (Tabela 2) e do CMSD pelos animais (Tabela 4).

Não foram observadas diferenças significativas $(\mathrm{P}>0,05)$ entre as médias do $\mathrm{CED}$, expresso nas diferentes formas, nos dois tratamentos. Houve tendência de melhoria neste parâmetro com o corte a $45 \mathrm{~cm}$ favoreceu o CED, resultado da maior concentração de grãos na massa ensilada (Tabela 3) e da maior digestibilidade (Tabela 2).

Tabela 5 - Consumo médio diário de energia digestível (CED), expresso por Mcal/animal (CEDD), por $100 \mathrm{~kg}$ de peso vivo (CEDP) e por unidade de peso metabólico (CEDM), de bezerros confinados, de acordo com o tratamento e período de avaliação

Table 5 - Average daily digestible energy intake (DEI), expressed in Mcal per animal (DEID), per $100 \mathrm{~kg}$ of live weight (DEIP), per unit of metabolic weight (DEIM), of confined calves, according to treatment and evaluation period

\begin{tabular}{|c|c|c|c|}
\hline \multirow[t]{2}{*}{$\begin{array}{l}\text { Tratamento } \\
\text { Treatment }\end{array}$} & \multicolumn{2}{|c|}{$\begin{array}{l}\text { Períodos de avaliação } \\
\text { Evaluation periods }\end{array}$} & \multirow[t]{2}{*}{$\begin{array}{l}\text { Média } \\
\text { Mean }\end{array}$} \\
\hline & $\begin{array}{l}12 / 06 \text { a } 13 / 08 \\
06 / 12 \text { to } 08 / 13\end{array}$ & $\begin{array}{l}14 / 08 \text { a } 16 / 10 \\
08 / 14 \text { to } 10 / 16\end{array}$ & \\
\hline \multicolumn{4}{|c|}{$\begin{array}{c}\mathrm{CEDD}(\mathrm{Mcal} / \mathrm{dia}) \ldots \ldots \\
D E I D\end{array}$} \\
\hline $\begin{array}{l}\text { Corte baixo } \\
\text { Low cut }\end{array}$ & 18,77 & 24,47 & $21,62^{\mathrm{A}}$ \\
\hline $\begin{array}{l}\text { Corte alto } \\
\text { High cut }\end{array}$ & 20,81 & 26,85 & $23,83^{A}$ \\
\hline $\begin{array}{l}\text { Média } \\
\text { Mean }\end{array}$ & $19,79^{b}$ & $25,66^{\mathrm{a}}$ & \\
\hline \multicolumn{4}{|c|}{$\begin{array}{c}D \ldots \ldots \\
D E I P\end{array}$} \\
\hline $\begin{array}{l}\text { Corte baixo } \\
\text { Low cut }\end{array}$ & 7,63 & 7,57 & $7,60^{\mathrm{A}}$ \\
\hline $\begin{array}{l}\text { Corte alto } \\
\text { High cut }\end{array}$ & 8,26 & 7,93 & $8,09^{\mathrm{A}}$ \\
\hline Média & $7,95^{\mathrm{a}}$ & $7,75^{\mathrm{b}}$ & \\
\hline \multicolumn{4}{|c|}{$\begin{array}{c}\ldots . \operatorname{CEDM}\left(\mathrm{g} / \mathrm{kg}^{0,75}\right) \\
D E I M\end{array}$} \\
\hline $\begin{array}{l}\text { Corte baixo } \\
\text { Low cut }\end{array}$ & 0,302 & 0,321 & $0,312^{\mathrm{A}}$ \\
\hline $\begin{array}{l}\text { Corte alto } \\
\text { High cut }\end{array}$ & 0,329 & 0,340 & $0,335^{\mathrm{A}}$ \\
\hline $\begin{array}{l}\text { Média } \\
\text { Mean }\end{array}$ & $0,316^{\mathrm{b}}$ & $0,330^{\mathrm{a}}$ & \\
\hline $\begin{array}{ll}\mathrm{A}, \mathrm{B}, \mathrm{a}, \mathrm{b} & \text { Médi } \\
& \text { rente } \\
& \text { difere } \\
A, B, a, b & \end{array}$ & $\begin{array}{l}\text {, na coluna, se } \\
\text { e médias, na lin } \\
\text { tes para cada }\end{array}$ & $\begin{array}{l}\text { as de letras mail } \\
\text { eguidas de letras } \\
\text { vel, diferem }(P<\end{array}$ & $\begin{array}{l}\text { Ulas dife- } \\
\text { inúsculas } \\
\text { 5). }\end{array}$ \\
\hline $\begin{array}{l}\text { Mean } \\
\text { mean } \\
\text { differ }\end{array}$ & $\begin{array}{l}\text { within a column, } f \\
\text { within a line, fol } \\
t(P<.05)\end{array}$ & $\begin{array}{l}\text { ed by different capi } \\
\text { by different sma }\end{array}$ & $\begin{array}{l}\text { letters and } \\
\text { etters, are }\end{array}$ \\
\hline
\end{tabular}


na relação volumoso:concentrado de 65:35, contendo silagem de sorgo AG-2002 e AG-2006, respectivamente, no entanto, o autor ressalta que a maior concentração energética da silagem do AG-2006 favoreceu para esta diferença percentual de $12,5 \%$.

Na média geral, os resultados do presente trabalho para o parâmetro CA $(6,17$ para o corte baixo e 5,60 para o corte alto) ficaram abaixo dos relatados por Silva (1999), que encontrou o valor médio de 8,41 para novilhos Charolês, Nelore e cruzas, alimentados com dietas contendo silagem de sorgo do AG-2006 e por Silva et al. (1999a), que observaram o valor de 6,53 para novilhos F1 Pardo Suíço x Nelore e 7,35 para novilhos puros Nelore alimentados com dietas contendo silagem de sorgo do AG-2006.

Com relação à $\mathrm{CE}$, a média geral verificada no presente trabalho (17,53 para o corte baixo e 17,31 para o corte alto) foi semelhante àquela encontrada por Restle et al. (1997), com consumo médio de 17,3 Mcal/kg de PV para novilhos Hereford superprecoce em regime de confinamento recebendo uma dieta com silagem de sorgo na relação volumoso:concentrado média de 55:45. Restle et al. (1999b), avaliando o desempenho de novilhos Hereford superprecoce puros e cruzados, observaram CE de $19,84 \mathrm{Mcal} / \mathrm{kg}$ de PV, com uma dietaà base de silagem de sorgo, com relação volumoso: concentrado de 46:54.

Analisando os períodos de confinamento, verifica-se na Tabela 6 que o GMD foi igual $(\mathrm{P}>0,05)$ nos dois períodos. $\mathrm{O}$ aumento no nível de concentrado na dieta de 40 para $50 \%$, no segundo período, permitiu que os animais mantivessem o mesmo ritmo de ganho de peso verificado no primeiro período. No entanto, a conversão alimentar piorou, o mesmo ocorreu com a eficiência de transformação de ED em ganho de peso. O CMSD $/ \mathrm{kg}$ de ganho de peso que foi de 5,33 no primeiro período passou para 6,44 no segundo período. Embora a concentração de ED tenha aumentado de 2,323 (corte a $14 \mathrm{~cm}$ ) para 2,784 Mcal $/ \mathrm{kg}$ de MS (corte a $45 \mathrm{~cm}$ ) e o consumo médio de energia digestível tenha aumentado de 19,79 para $25,66 \mathrm{Mcal} /$ dia $(\mathrm{P}<0,05)$ (Tabela 5), a eficiência alimentar decresceu $(5,33$ para o primeiro período e 6,44 para o segundo período). Isto se deve, provavelmente, ao incremento da energia de mantença, que é proporcional ao peso vivo do animal (NRC, 1984), e em função da composição do ganho de peso, que passa a ter maior porção de gordura, à medida que o animal vai atingindo condições de abate.

O peso dos animais no final do período experi- mental foi de 382,7 e $363,0 \mathrm{~kg}$ para o tratamento com cortes alto e baixo, respectivamente. $O$ peso de carcaça fria e a espessura de gordura de cobertura, citadas na mesma ordem, foram de 204,5 kg e 3,66 mm, e 196,7 kg e 4,02 mm. Verificou-se que os animais de ambos os tratamentos apresentaram peso de carcaça e espessura de gordura de cobertura acima dos $180 \mathrm{~kg}$ e de $3 \mathrm{~mm}$ exigidos pelos frigoríficos no sul do país, para animais superprecoce.

\section{Conclusões}

A silagem de sorgo AG-2006 produzida por plantas cortadas a $45 \mathrm{~cm}$, apresentou menores teores de FDN e FDA e maior concentração de energia digestível por $\mathrm{kg}$ de MS.

Recomenda-se a inclusão de silagem de sorgo colhida a altura de $45 \mathrm{~cm}$ na dieta de bovinos jovens em confinamento, por proporcionar melhor conversão alimentar durante a terminação.

\section{Literatura Citada}

AGRICULTURAL RESEARCH COUNCIL - ARC. The nutrients requirements of ruminants livestock. Technical review by on Agricultural Research Council Working Party, London, 1980. 351p.

ASSOCIATION OF OFFICIAL ANALYTICAL CHEMISTS A.O.A.C. Official methods of analysis. 14.ed. Washington, D.C., 1984. 1141p.

BRASIL. Ministério da Agricultura. Levantamento de reconhecimento de solos do Rio Grande do Sul. Rio de Janeiro: Departamento Regional de Pesquisa Agropecuária: Divisão de Pesquisas Pedológicas. 1973. 431p. (DNPEA, Boletim Técnico 30).

DEMARCHI, J.J.A.A.; BOIN, C.; BRAUN, G. A cultura do sorgo (Sorghum bicolor L. Moench) para produção de silagens de alta qualidade. Zootecnia, v.33, n.3, p.111-136, 1995.

EIFERT, E.C. Silagens de sorgo e de triticale associadas a níveis de concentrado para alimentação de terneiros de corte desmamados precocemente. Santa Maria: Universidade Federal de Santa Maria, 2000. 150p. Dissertação (Mestrado em Zootecnia) - Universidade Federal de Santa Maria, 2000.

ELIZALDE, H.F. El valor nutritivo de los ensilages. Revista Argentina Producción Animal, v.15, n.1, p.103-121, 1995.

FLORES, J.L.C. Desempenho em confinamento e características de carcaça e da carne de bovinos de diferentes grupos genéticos abatidos aos quatorze meses. Santa Maria: Universidade Federal de Santa Maria, 1997. 109p. Dissertação (Mestrado em Zootecnia) - Universidade Federal de Santa Maria, 1997.

HART, S.P. Effects of altering the grain content of sorghum silage on its nutritive value. Journal of Animal Science, v.68, n.11, p.3832-3842, 1990.

McDONALD, P.; HENDERSON, N.; HERON, S. The biochemistry of silage. 2.ed. Chalcombe publications, 1991. 339p.

MERTENS, D.R. Análise de fibra e sua utilização na avaliação 
de alimentos e formulação de rações. In: SIMPÓSIO INTERNACIONAL DE RUMINANTES, REUNIÃO ANUAL DA SOCIEDADE BRASILEIRA DE ZOOTECNIA, 29., 1992, Lavras. Anais... Lavras: Sociedade Brasileira de Zootecnia, 1992. p. 188-219.

MERTENS, D.R. Regulation of forage intake. In: FAHEY Jr., G.C.; MOSER, L.E.; MERTENS, D.R. (Eds.) Forage quality, evaluation and utilization. Madison: American Society of Agronomy, Crop Science of America, Soil Science of America, 1994. p.450-493.

MOREnO, J.A. Clima do Rio Grande do Sul. Porto Alegre: Secretaria da Agricultura. 1961. 41p.

NATIONAL RESEARCH COUNCIL - NRC. Nutrient requirements of domestic animals. 6.ed. rev. Washington, D.C.: National Academy Press, 1984. 90p.

NEUMANN, M. Caracterização agronômica quantitativa e qualitativa da planta, qualidade de silagem e análise econômica em sistema de terminação de novilhos confinados com silagem de diferentes híbridos de sorgo (Sorghum bicolor, L. Moench). Santa Maria: Universidade Federal de Santa Maria, 2001. 208p. Dissertação (Mestrado em Zootecnia) - Universidade Federal de Santa Maria, 2001.

PEREIRA, O.G.; OBEID, J.A.; GOMIDE, J.A. et al. Produtividade de uma variedade de milho (Zea mays L.) e de três variedades de sorgo (Sorghum bicolor L. Moench) e o valor nutritivo de suas silagens. Revista Brasileira de Zootecnia, v.22, n.1, p.31-38, 1993.

PIMENTEL, J.J.O.; SILVA, J.F.C. da; VALADARES FILHO, S.C. Efeito da suplementação protéica no valor nutritivo de silagens de milho e sorgo. Revista Brasileira de Zootecnia, v.27, n.5, p.1042-1049, 1998.

PUND, W.A. Finishing yearling steers with high energy grain sorghum silage. Mississipi Agric. Exp. Sta. Bull, 1970. p. 780 .

RESTLE, J.; FLORES, J.L.C.; VAZ, F.N. et al. Desempenho em confinamento, do desmame ao abate aos quatorze meses, de bovinos inteiros ou castrados, produzidos por vacas de dois anos. Ciência Rural, v.27, n.4, p.651-655, 1997.

RESTLE, J.; BRONDANI, I.L.; BERNARDES, R.A.C. O novilho superprecoce. In: RESTLE, J. (Ed.) Confinamento, pastagens e suplementação para produção de bovinos de corte. Santa Maria: UFSM, 1999a. p.191-214.

RESTLE, J.; BRONDANI, I.L.; FLORES, J.L.C. et al. Desempenho de genótipos de novilhos para abate aos catorze meses, gerados por fêmeas de dois anos. Pesquisa Agropecuária Brasileira, v.34, n.11, p.2123-2128, 1999 b.

RESTLE, J.; EIFERT, E.C.; BRONDANI, I.L et al. Produção de terneiros para abate aos 12 meses, alimentados com silagens de milho a duas alturas de corte, associadas a dois níveis de concentrado. In: REUNIÃO ANUAL DA SOCIEDADE BRASILEIRA DE ZOOTECNIA, 36, 1999c, Porto Alegre. Anais... São Paulo: SBZ/Gmosis, [1999c] 17par. CD-ROM. Nutrição de ruminantes. NUR-143.

RESTLE, J.; ALVES FILHO, D.C.; NEUMANN, M. Eficiência na terminação de bovinos de corte. In: RESTLE, J. (Ed.) Eficiência na produção de bovinos de corte. Santa Maria: Universidade Federal de Santa Maria, 2000a. p.277-303.
RESTLE, J.; ALVES FILHO, D.C.; BRONDANI, I.L. et al. Palha de soja (Glicine max) como substituto parcial da silagem de sorgo forrageiro (Sorghum bicolor L. Moench) na alimentação de terneiros de corte confinados. Ciência Rural, v.30, n.2, p.319-324, 2000b.

SAS INSTITUTE. SAS/STAT user's guide: statistics. 4.ed. Version 6, v.2. Cary: 1993. 943p.

SILVA, N.L.Q. Terminação de novilhos em confinamento alimentados com silagem de dois híbridos de sorgo (Sorghum bicolor L. Moench) associados a três níveis de concentrado. Santa Maria: Universidade Federal de Santa Maria, 1999. 100p. Dissertação (Mestrado em Zootecnia) Universidade Federal de Santa Maria, 1999.

SILVA, F.F.; GONÇALVES, L.C.; RODRIGUEZ, J.A.S. et al. Qualidade de silagens de híbridos de sorgo (Sorghum bicolor (L.) Moench) de portes baixo, médio e alto com diferentes proporções de colmo+folhas/panícula. 2. Avaliação do valor nutritivo. Revista Brasileira de Zootecnia, v.28, n.1, p.21-29, 1999a.

SILVA, J.M.; FEIJÓ, G.L.D.; THIAGO, L.R.L.S. et al. Desempenho animal e avaliação do potencial produtivo de forragens para ensilagem, por intermédio de diferentes fontes de suplementação nitrogenada. Revista Brasileira de Zootecnia, v.28, n.3, p.642-653, 1999 b.

TILLEY, J.M.; TERRY, R.A. A two-stage technique for the in vitro digestion of forage crops. Journal British Grassland Society, v.18, p.104-111, 1963.

VALADARES FILHO, R.F.D.; GONÇALVES, L.C.; RODRIGUEZ, N.M. et al. Níveis de proteína em dietas de bovinos. 1. Consumo e digestibilidade aparentes totais e parciais. Revista Brasileira de Zootecnia, v.26, n.6, p.1252-1258, 1997.

Van SOEST, P.J.; WINE, R.H. Use of detergents in analysis of fibrous feeds. IV. Determinations of plant cell-wall constituents. Journal of Association Official Analysis Chemists, v.50, p.50, 1967.

VARGAS Jr., F.M.; SANCHEZ, L.M.B.; PASCOAL, L.L. et al. Desempenho de terneiros de corte alimentados com diferentes fontes protéicas e com silagem de sorgo colhida a diferentes alturas de corte. In: REUNIÃO ANUAL DA SOCIEDADE BRASILEIRA DE ZOOTECNIA, 34., 1998, Botucatu. Anais... Botucatu: Sociedade Brasileira de Zootecnia, 1998. p.558-560.

ZAGO, C.P. Cultura de sorgo para produção de silagem de alto valor nutritivo. In: PEIXOTO, A.M.; MOURA, J.C.; FARIA, V.P. (Eds.) In: Anais do simpósio sobre nutrição de bovinos. 4.ed. Piracicaba: Fundação de Estudos Agrários Luiz de Queiroz, 1991. p.169-217.
Recebido em: 12/06/01 Aceito em: 07/05/02 